\title{
Molecular characterization of the Corynebacterium pseudotuberculosis hsp60-hsp10 operon, and evaluation of the immune response and protective efficacy induced by hsp60 DNA vaccination in mice
}

\author{
Marcilia P Costa1,2, John A McCulloch ${ }^{3}$, Síntia S Almeida', Fernanda A Dorella', Cristina T Fonseca4, \\ Diana M Oliveira ${ }^{2}$, Maria FS Teixeira ${ }^{2}$, Ewa Laskowska ${ }^{5}$, Barbara Lipinska ${ }^{5}$, Roberto Meyer ${ }^{6}$, Ricardo W Portela ${ }^{6}$, \\ Sérgio C Oliveira ${ }^{1}$, Anderson Miyoshi ${ }^{1}$ and Vasco Azevedo ${ }^{1 *}$
}

\begin{abstract}
Background: Heat shock proteins (HSPs) are important candidates for the development of vaccines because they are usually able to promote both humoral and cellular immune responses in mammals. We identified and characterized the hsp60-hsp10 bicistronic operon of the animal pathogen Corynebacterium pseudotuberculosis, a Gram-positive bacterium of the class Actinobacteria, which causes caseous lymphadenitis (CLA) in small ruminants.

Findings: To construct the DNA vaccine, the hsp60 gene of C. pseudotuberculosis was cloned in a mammalian expression vector. BALB/c mice were immunized by intramuscular injection with the recombinant plasmid (pVAX1/ hsp60).
\end{abstract}

Conclusion: This vaccination induced significant anti-hsp60 lgG, IgG1 and lgG2a isotype production. However, immunization with this DNA vaccine did not confer protective immunity.

\section{Findings}

Corynebacterium pseudotuberculosis is a facultative, intracellular, Gram-positive bacterium of the class Actinobacteria, which also includes the genera Mycobacterium, Nocardia and Rhodococcus. The latter three genera, together with Corynebacterium, form a group of potentially pathogenic species termed the CMN group. Corynebacterium pseudotuberculosis is the etiological agent of caseous lymphadenitis (CLA), or cheesy gland, which affects small ruminants (sheep and goats) and occasionally other hosts. This chronic disease is pathognomonically characterized by the formation of suppurative abscesses in superficial and internal lymph nodes. In

\footnotetext{
* Correspondence: vasco@icb.ufmg.br

'Departamento de Biologia Geral. Instituto de Ciências Biológicas. Universidade Federal de Minas Gerais. Av. Antonio Carlos, 6627 - Pampulha, CP 486, CEP 31.270-901. Belo Horizonte- MG, Brazil
}

Full list of author information is available at the end of the article severe cases, these abscesses are also found in internal organs, such as the lungs, kidneys, liver and spleen, characterizing visceral CLA [1]. The economic relevance of CLA, its widespread occurrence, and a lack of knowledge regarding its molecular mechanisms of virulence, have prompted the investigation of its pathogenesis with the aim to develop efficient treatment strategies against this disease [2].

Chemotherapeutic treatment of CLA is difficult because the bacteria are shielded within granulomas, where they are relatively protected from antibiotic drugs [3]. Therefore, attempts to control CLA usually entail immunoprophylaxis by vaccination. Various strategies have been used for developing vaccines against CLA, including the use of inactivated or attenuated $C$. pseudotuberculosis strains [4,5], fractions of bacterial cells containing bacterial antigens, antigens from culture supernatants, and DNA vaccines [6]. None of the
C Biomed Central 
currently commercially available vaccines for C. pseudotuberculosis provide effective protection against CLA [7].

Heat shock proteins (HSPs), or molecular chaperones, are traditionally classified according to their molecular weight; they are highly conserved proteins, abundantly expressed in eukaryotic and prokaryotic organisms [8]. These proteins are expressed in unstressed cells at low levels, and play an important role in cell survival both under normal physiological conditions, during various phases of the cell cycle, cellular differentiation and growth, and under stress conditions, such as heat shock [9]. Heat shock proteins are considered immunologically important due to the fact that they are recognized by the host in bacterial, fungal, and parasitic infections and are therefore capable of inducing strong humoral and cellular immune responses in mammals [10].

Several studies have shown that these versatile proteins can be used as antigens for the development of vaccines against diseases. In the case of infectious diseases, HSPs could play a dual role in vaccine development. Pathogen-derived HSPs can be used as vaccine antigens, and host- and pathogen-derived HSPs can be used as adjuvants $[11,12]$. Strategies to more effectively induce immunity with HSPs include the use of DNA vaccines. HSP-based DNA vaccines have been effective in several immunization trials against Mycobacterium spp. infection [12].

The Hsp60 protein of C. pseudotuberculosis, using a protein subunit as immunogen against CLA, failed to confer protection against infection with C. pseudotuberculosis in mice [13]. Using an alternative strategy, we assessed the feasibility of using DNA encoding $h s p 60$ for protection against experimental challenge with $C$. pseudotuberculosis.

\section{Methods}

Bacterial strains, growth conditions and plasmids

All bacterial strains, plasmids and PCR primers used in this study are listed in Table 1. Escherichia coli TOP10 was grown in Luria-Bertani broth (LB, Difco Laboratories, Detroit, USA) at $37^{\circ} \mathrm{C}$ with stirring for $18 \mathrm{~h}$. Plasmid-containing transformants were selected by the addition of ampicillin (Invitrogen, San Diego, CA) and X-Gal (Invitrogen, San Diego, CA) to the media. The supplement concentrations were ampicillin $(100 \mu \mathrm{g} / \mathrm{mL})$ and X-Gal $(40 \mu \mathrm{g} / \mathrm{mL})$.

Isopropyl- $\beta$-D-thiogalactopyranoside (IPTG) was used at a final concentration of $1 \mathrm{mM}$ in complementation experiments.

Corynebacterium pseudotuberculosis biovar ovis strain T1 was aerobically grown in brain heart infusion broth (BHI, Acumedia Manufacturers, Inc., Baltimore, MD, USA) and on $1.5 \%(\mathrm{w} / \mathrm{v}) \mathrm{BHI}$ agar plates at $37^{\circ} \mathrm{C}$ for 48 $72 \mathrm{~h}[14]$.

\section{DNA isolation}

All DNA templates were prepared with genomic DNA isolated by collecting a bacterial cell pellet from culture, as previously described [14]. Briefly, an aliquot of $20 \mathrm{~mL}$ from a 48 to $72 \mathrm{~h}$ culture was centrifuged at $4^{\circ} \mathrm{C}$ and $2000 \times g$ for $20 \mathrm{~min}$. Cell pellets were resuspended in 1 $\mathrm{mL}$ of Tris/EDTA/RNase [10 mM Tris/HCl (pH 7.0), 10 mM EDTA (pH 8.0), $300 \mathrm{mM} \mathrm{NaCl}, 50 \mathrm{mg}$ RNaseA $\left.\mathrm{mL}^{-1}\right]$ and centrifuged again under the same conditions. Supernatants were discarded and the pellets were resuspended in $1 \mathrm{~mL}$ of TE/lysozyme. Samples were then incubated at $37^{\circ} \mathrm{C}$ for $30 \mathrm{~min} ; 30 \mu \mathrm{L}$ of $30 \%(\mathrm{w} / \mathrm{v})$ sodium $\mathrm{N}$-lauroylsarcosine (sarcosyl) were added, and the mixture was incubated for $20 \mathrm{~min}$ at $65^{\circ} \mathrm{C}$, followed by incubation for $5 \mathrm{~min}$ at $4^{\circ} \mathrm{C}$. DNA was purified using phenol/chloroform/isoamyl alcohol and precipitated

Table 1 Strains and plasmids used in this study.

\begin{tabular}{|c|c|}
\hline \multicolumn{2}{|l|}{ Description or sequence } \\
\hline \multicolumn{2}{|l|}{ Strain } \\
\hline $\begin{array}{l}\text { Corynebacterium pseudotuberculosis } \\
\text { biovar ovis }\end{array}$ & $\begin{array}{l}\text { T1 (virulent strain isolates from goats; obtained from the Universidade Federal da Bahia, UFBA, Brazil). } \\
\text { MIC-6 (virulent strain isolate from goats; obtained from the Laboratório de Genética Celular e Molecular -LGCM, } \\
\text { UFMG, Brazil). }\end{array}$ \\
\hline E. coli & $\begin{array}{l}\text { TOP10 [F- mcrA } \Delta(\text { mrr-hsdRMS-mcrBC) } \phi 80 \text { lacZ } \Delta \text { M15 } \triangle \text { lacX74 nupG recA1 araD139 } \Delta \text { (ara-leu)7697 galE15 galK16 } \\
\text { rpsL(StrR) endA1 } \lambda \text {-] Invitrogen. } \\
\text { B178 groEL44 mutant ( } \Delta \text { groEL44) characterized by Zeilstra-Ryalls et al [19]. }\end{array}$ \\
\hline \multicolumn{2}{|l|}{ Plasmid } \\
\hline pTopo ${ }^{\circledR}$ Cloning vector & Cloning vector - ColE1/Ap ${ }^{r}$ - Invitrogen. \\
\hline $\operatorname{pVAX1}^{\circ}$ Vector & Eukaryotic expression vector - pUC/Km - Invitrogen. \\
\hline pTopo/hsp60 & $\begin{array}{l}\text { Cloning vector with the C. pseudotuberculosis hsp60 gene inserted in the BamHI and Hindlll restriction sites of } \\
\text { the vector. }\end{array}$ \\
\hline pProEx-Hta/hsp60 & Prokaryotic expression vector containing the C. pseudotuberculosis hsp60 gene [13]. \\
\hline pVAX1/hsp60 & Eukaryotic expression vector containing the C. pseudotuberculosis hsp60 gene. \\
\hline
\end{tabular}


with ethanol. DNA concentrations were determined spectrophotometrically.

\section{PCR amplification and cloning}

PCR reagents, restriction endonucleases, and ligation reagents used in this study were all purchased from Invitrogen, San Diego, CA. Both genes were amplified by PCR using genomic DNA of C. pseudotuberculosis as a template, with primers that were designed based on the DNA sequence of paralogs of $C$. diphtheriae NCTC 13129 (NCBI Acc. GeneID: 2648771 and NCBI Acc. GeneID: 2648772). The C. pseudotuberculosis hsp60 gene was amplified by PCR using the following primers: 5'- GATGGCAAAGCTGATTGCA -3' (sense orientation) and 5'- TTAGTGGTGGTGATGGTG -3' (antisense orientation). The PCR assays were carried out in a final reaction volume of $50 \mu \mathrm{L}$, containing $20 \mathrm{ng}$ genomic DNA, $2 \mu \mathrm{M}$ of each of the primers, $1 \times$ PCR Buffer II and $1 \mathrm{U}$ AccuPrime taq DNA polymerase. Amplification was run in a thermal cycler (PTC-100, MJ Research, Inc.) as follows: one cycle of $95^{\circ} \mathrm{C}$ for $5 \mathrm{~min}$; 29 cycles of $95^{\circ} \mathrm{C}$ for $1 \mathrm{~min}, 50^{\circ} \mathrm{C}$ for $40 \mathrm{~s}$, and $68^{\circ} \mathrm{C}$ for $2 \mathrm{~min} 30 \mathrm{~s}$; and a final extension step at $68^{\circ} \mathrm{C}$ for $7 \mathrm{~min}$. The hsp60 fragment was purified from bands in $1.0 \%$ (w/v) agarose gels using the Consert TM Rapid Gel Extraction System kit (Gibco-BRL, Gaithersburg, MD, USA). The retrieved DNA fragment was then ligated into the $\mathrm{pCR}^{\circledR} 2.1$-TOPO ${ }^{\circledR}$ vector, as described in the manufacturer's protocol. The recombinant plasmid $\left(\mathrm{pCR}^{\circledR} 2.1-\mathrm{TOPO}^{\circledR} / h s p 60\right)$ was then introduced into competent E. coli TOP10 cells, and single recombinant colonies were selected. Plasmid DNA was isolated from cells by the alkaline lysis method [15]. The presence of the inserted DNA fragment was confirmed by sequencing, using the DYEnamic ET Dye Terminator kit (Amersham Biosciences, Piscataway, NJ, USA).

To verify operon structure, the $h s p 10$ gene and intergenic regions of the operon were amplified using the following primer pair: 5'- GTGGCTAACGTCAATATCAAGCC -3' (sense orientation) (designed based on the DNA sequence of paralogs of $C$. diphtheria NCTC 13129) and 5'- CTTCAGGATGCCTTCACGGG -3' (antisense orientation) (designed based on the DNA sequence of the C. pseudotuberculosis hsp60 gene). The PCR assays were carried out in a final reaction volume of $50 \mu \mathrm{L}$ containing $20 \mathrm{ng}$ genomic DNA, $2 \mu \mathrm{M}$ of each of the primers, $1 \times$ PCR Buffer II and 1 U AccuPrime taq DNA polymerase. Amplification was performed with a thermal cycler (PTC-100, MJ Research, Inc.) as follows: one cycle of $95^{\circ} \mathrm{C}$ for $3 \mathrm{~min} ; 29$ cycles of $95^{\circ} \mathrm{C}$ for $1 \mathrm{~min}, 50^{\circ} \mathrm{C}$ for $40 \mathrm{~s}$, and $72^{\circ} \mathrm{C}$ for $1 \mathrm{~min} 30 \mathrm{~s}$; and a final extension step at $72^{\circ} \mathrm{C}$ for $5 \mathrm{~min}$. The amplicon containing $h s p 10$ was also purified, cloned, transformed, and sequenced as described above.

\section{Bioinformatics and comparative genomics}

Sequence homology analysis was carried out against nucleotide and protein databases available in GenBank http://www.ncbi.nlm.nih.gov/, using the Blast tool http://www.ncbi.nlm.nih.gov/BLAST/ [16]. Multiple sequence alignments and analysis were performed using the ClustalW algorithm http://www.ebi.ac.uk/clustalw/. The predicted amino acid sequences were analyzed to identify conserved motifs, using the Conserved Domains program http://www.ncbi.nlm.nih.gov/Structure/cdd/ wrpsb.cgi and the ExPaSy ScanProsite program http:// www.expasy.org/tools/scanprosite/. For three-dimensional modeling, we employed MODELLER http://salilab.org/modeller/modeller.html [17]. The isoelectric point (Ip) and molecular weight $(\mathrm{Mw})$ were predicted with software found on the ExPaSy website http://web. expasy.org/compute_pi/ [18].

\section{Functional characterization of the C. pseudotuberculosis hsp60 gene}

To examine the functional activity of the C. pseudotuberculosis hsp60 gene, E. coli B178groEL44 mutant ( $\triangle$ groEL44) was transformed with a pProEx-Hta/hsp60 plasmid constructed by Pinho et al [13]. The E. coli $\triangle$ groEL44 mutant is a strain that bears a temperaturesensitive allele of groEL, namely groEL44. This mutant strain is unable to propagate bacteriophages $\gamma$, T4 or T5 [19]. Two phenotypes were analyzed in this complementation assay: heat stress resistance and inability of $\gamma_{c} \mathrm{Ib} 2$ phage to grow without the protein coded by the hsp 60 (groEL) gene, as described by Kumar et al [20], with adaptations for use in our study. First, the empty vector (pProEx-Hta) and the recombinant vector (pProEx-Hta/ hsp60) were transformed into the E. coli wild-type B178 and $\triangle g r o E L 44$ strains. To investigate the effect of temperature on protein expression, the bacteria were grown in LB broth containing ampicillin and IPTG. The protein was visualized in an SDS-polyacrylamide gel [21]. Aliquots of $3 \mu \mathrm{L}$ of the induced cultures were plated on LB, with and without IPTG, in dilutions from $10^{-1}$ to $10^{-6}$, and the plates were incubated at 30 and $42^{\circ} \mathrm{C}$. Finally, to assess the growth of the $\gamma c \mathrm{Ib} 2$ phage, E. coli $\triangle$ groEL44 was transformed with the empty and recombinant vectors (groEL44[pProEX-Hta] and groEL44 [pProEx-Hta/hsp60]), while the wild-type E. coli was transformed with the empty vector (B178[pProEX-Hta]). Dilutions of the phage $\left(10^{-1}, 10^{-2}, 10^{-3}\right.$ and $\left.10^{-4}\right)$ were made. Aliquots of the dilutions were plated on LB containing these transformants, with and without IPTG, and the plates were incubated at $30^{\circ} \mathrm{C}$ for $18 \mathrm{~h}$.

\section{Plasmid construction for the DNA vaccine}

The $h s p 60$ gene was amplified using primers containing restriction sites and the Kozak consensus sequence 
within the primer: 5'- AAGCTTACCATGGCAAAGATTGCATT - 3' (sense orientation) and 5'GGATCCTTAGTGGTGGTGATGGTG - 3' (antisense orientation), which include the HindIII and BamHI sites (underlined), respectively. The $h s p 60$ gene was amplified, cloned and transformed as described above. The recombinant plasmid $\left(\mathrm{pCR}^{\circledR} 2.1-\mathrm{TOPO}^{\circledR} / h s p 60\right)$ and the eukaryotic expression vector $\left(\mathrm{pVAX}^{\odot}\right)$ were submitted to HindIII/BamHI double digestion. The digested samples were analyzed by $1 \%$ agarose gel electrophoresis. DNA fragments were purified as described above. The purified DNA fragments were then subcloned into the pVAX1 vector. The components and conditions of the ligation reaction were according to the manufacturer's instructions. The presence and the correct size of the insert were confirmed by restriction enzyme digestion (EcoRI/HindIII). Both the empty vector (control) and the recombinant vector (pVAX1/hsp60) were introduced into competent $E$. coli TOP10, and single recombinants were selected. Control and pVAX1/hsp 60 vectors were isolated and purified using the EndoFree Plasmid Giga kit (Qiagen, Valencia, CA, USA). DNA concentration and purity were determined by absorbance at 260 and $280 \mathrm{~nm}$.

\section{Immunization and challenge}

BALB/c mice (6-8 weeks old) were divided into two groups of five mice each. Mice were pretreated with 10 $\mu \mathrm{M}$ cardiotoxin five days before the first DNA immunization, as previously described [22]. Each animal was immunized by injecting the quadriceps muscle with four doses of $100 \mu \mathrm{g}$ at 15-day intervals, with an empty vector (pVAX1; control) or a recombinant vector pVAX1/ hsp60. Blood samples from the mice were collected by retro-orbital plexus puncture 15, 30, 45 and 60 days after the first immunization. All mice were challenged intraperitoneally 21 days after the fourth vaccination with an infectious dose of $1 \pm 10^{6} \mathrm{CFU}$ of the MIC-6 strain of C. pseudotuberculosis. After challenge, the mice were monitored daily and the protective effect of the DNA vaccine was assessed by evaluation of the survival rate of the immunized animals. This experiment was performed twice to confirm the results.

\section{Determination of antibody levels}

To examine the humoral responses induced by pVAX1/ $h s p 60$, the levels of specific anti-hsp60 IgG, IgG1 and IgG2a isotypes in individual mouse sera were determined by ELISA. Flat-bottomed 96-well plates were coated with the C. pseudotuberculosis Hsp60 protein in $0.05 \mathrm{M}$ carbonate/bicarbonate buffer, $\mathrm{pH}$ 9.6, $(5 \mu \mathrm{g} / \mathrm{mL}$ per well) at $4^{\circ} \mathrm{C}$ for $18 \mathrm{~h}$. The plates were washed three times with PBS-0.05\% T20 (1X PBS, pH 7.4, 0.05\% Tween 20) and then blocked with PBS-0.05\% T20 containing $10 \%$ bovine serum albumin - BSA $(250 \mu \mathrm{L}$ per well) at room temperature for $2 \mathrm{~h}$. Plates were then washed three times with PBS- $0.05 \%$ T20 before addition of a 1 in 100 serum dilution $(100 \mu \mathrm{L}$ per well) from immunized mice. The plates were then incubated at room temperature for $1 \mathrm{~h}$, and subsequently washed three times with PBS-0.05\% T20. Afterwards, $100 \mu \mathrm{L}$ of peroxidase-conjugated anti-mouse IgG (1 in 5000), IgG1 ( 1 in 5000) and IgG2a (1 in 2000) antibodies were added per well (Southern Biotechnology, Birmingham, $\mathrm{AL}$ ), and the plates were incubated for $1 \mathrm{~h}$. The reaction was developed by adding $200 \mathrm{pmol}$ orthophenyldiamine (Sigma-Aldrich, Bornem, Belgium) for $15 \mathrm{~min}$ and stopped by the addition of $50 \mu \mathrm{L}$ of $6 \% \mathrm{H}_{2} \mathrm{SO}_{4}$ to each well. The plates were read at $492 \mathrm{~nm}$ with an automatic microplate reader (Bio-Rad, Hercules, CA).

\section{Statistical analysis}

All data were expressed as means \pm standard deviation (S.D.) and analyzed using GraphPad Prism, version 4.03, for Windows (GraphPad Software, San Diego, CA). Statistical differences between groups were identified using one-way ANOVA. A one-tailed Student's $t$-test was used to determine if there were significant differences between the experimental and control groups. A $P$ value of 0.05 or less was considered significant.

\section{Results}

Isolation and characterization of the C. pseudotuberculosis hsp60 and hsp10 genes

The C. pseudotuberculosis hsp60 gene was amplified by PCR using primers that were designed based on the genome of $C$. diphtheriae, because of the phylogenetic proximity between these two species. The full lengths of the DNA sequences that were amplified were 1,626 (hsp60) and 297 (hsp10) nucleotides. The nucleotide sequences of the C. pseudotuberculosis strain T1 $60 \mathrm{kDa}$ chaperonin and $10 \mathrm{kDa}$ chaperonin GroES coding sequences were deposited in GenBank under accession numbers AY781285 and DQ869271, respectively. These two genes are separated by a small sequence of $11 \mathrm{bp}$ (Figure 1). In order to obtain information on similarity with genes of other species, the corresponding sequences were subjected to BlastN. Similarity searches of nucleotide sequences of both genes revealed significant identity with other Corynebacterium species. The hsp60 gene was predicted to encode a putative protein consisting of 541 amino acid residues, with a predicted molecular weight (MW) of $57.4 \mathrm{kDa}$ and a theoretical isoelectric point (IP) of 4.91. The $h s p 10$ gene was predicted to encode a polypeptide of 98 amino acids, with a MW of $10.6 \mathrm{kDa}$ and an Ip of 4.49. In order to search for the putative identities and functions of these genes, the sequences were subjected to BlastX searches against 


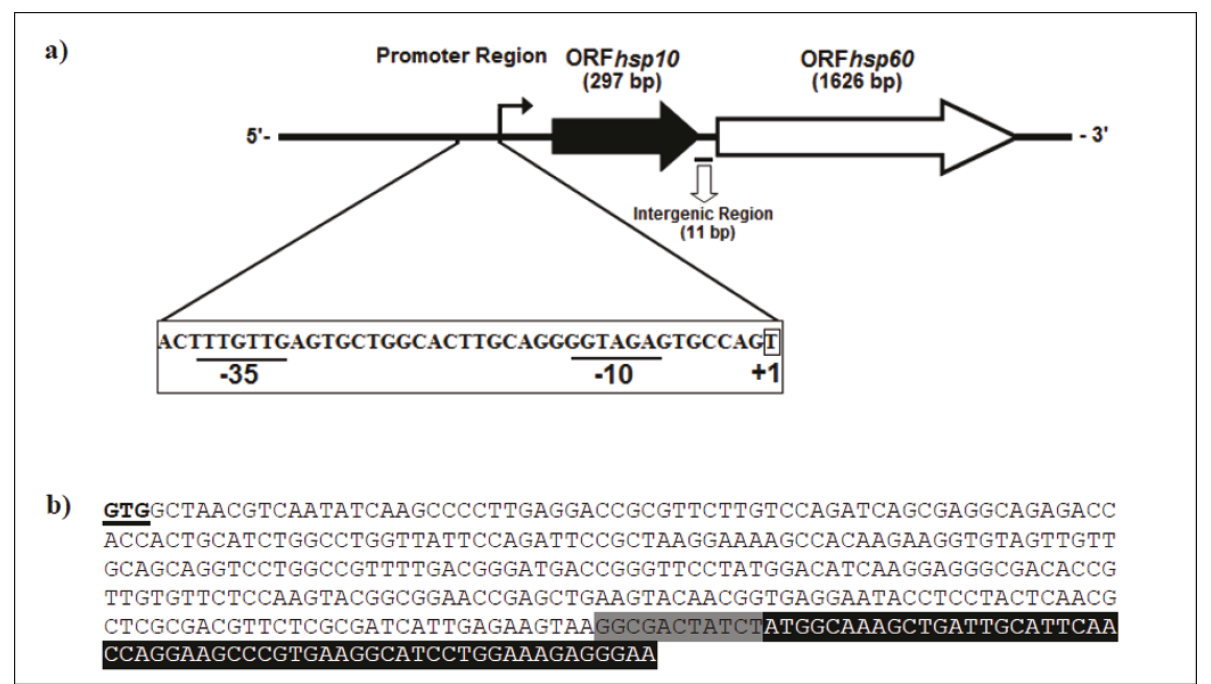

Figure 1 Characterization of the C. pseudotuberculosis bicistronic hsp60-hsp10 operon. In C. pseudotuberculosis, the hsp10 gene maps upstream of the $h s p 60$ gene, and the stop codon of hsp10 is separated from the start codon of hsp60 by a 11 bp intergenic region. The putative -10 and -35 hexamers and of the start point of transcription $(+1)$ are indicated; b) Nucleotide sequences of the C. pseudotuberculosis hsp60-hsp10 operon organization. The initial codon of hsp10 gene is underlined; the intergenic space (11 bp) between hsp60-hsp10 genes is shaded grey; and the initial sequence of the hsp60 gene is shaded black.

the protein database of GenBank. The putative Hsp60 protein displayed greater similarity to the Hsp60 protein of C. diphtheriae (89\%) and C. glutamicum (82\%), when compared to those of Nocardia (66.9\%) and Mycobacterium $(61 \%)$. The comparative alignment of primary amino acid sequences of Hsp60 homologues can be observed in Figure 2. The Hsp60 putative protein shows a motif characterized by a histidine-rich C-terminal. In order to compare the structure of Hsp60 protein of $C$. pseudotuberculosis with that of other chaperonins, a three-dimensional (3D) model was predicted based on PDB-related structures (Figure 3). The protein was found to have high sequence similarity (54\% identity) with chaperonins of other bacteria.

\section{Functional characterization of $h s p 60$}

The GroEL mechanism is universally conserved in prokaryotic species; consequently, paralogous copies of GroEL may result in redundancy of chaperonin function in these organisms. In E. coli, the development of phage lambda $(\gamma)$ requires a functional GroEL/S system. GroEL was originally identified as the host factor responsible for phage $\gamma$ capsid protein assembly and was subsequently shown to be essential for cell viability [20]. We used a complementation test to functionally characterize the $h s p 60$ gene (groEL gene) of C. pseudotuberculosis (Figure 4). Two E. coli strains were used for this purpose: the wild-type B178 strain and a $\triangle$ groEL44 mutant. We observed that the mutant transformed with the pProEx-Hta/hsp60 vector only grew at the $10^{-1}$ dilution, when incubated at $30^{\circ} \mathrm{C}$. When incubation was at $42^{\circ} \mathrm{C}$, bacterial growth was not observed (Figure $4 \mathrm{~b}$ ). The $\triangle$ groEL44 mutant, incubated at $30^{\circ} \mathrm{C}$, was also not phenotypically restored in a phage experiment. The expression of C. pseudotuberculosis hsp60 (groEL) did not promote phage development (Figure 4c).

\section{Anti-Hsp60 antibody response and protective efficacy of the DNA vaccine in a murine model}

Vaccination with plasmid DNA encoding hsp60 induced significant levels of anti-Hsp60 IgG, IgG1 and IgG2a antibodies in BALB/c mice, after the second immunization, compared to levels in mice vaccinated with the empty vector (Figure 5). Increased antibody responses following boosting were observed for all the isotypes. The levels of IgG1 and IgG2a at 15, 30, 45 and 60 days after the first immunization and the IgG1/IgG2a ratio were recorded (Table 2). The results suggest a Th2-type immune response, induced by pVAX1/hsp 60 vaccination, at 15 days after the first immunization, with a decrease of the IgG1/IgG2a ratio at 30, 45 and 60 days after the first immunization.

\section{Protection studies}

DNA vaccine protection studies were carried out in mice to test the potential of $h s p 60$ for this purpose. All the animals died 12 days after challenge with the wildtype C. pseudotuberculosis MIC-6 strain. The mice began to display clinical signs of morbidity three days after infection; during the first two weeks the animals 


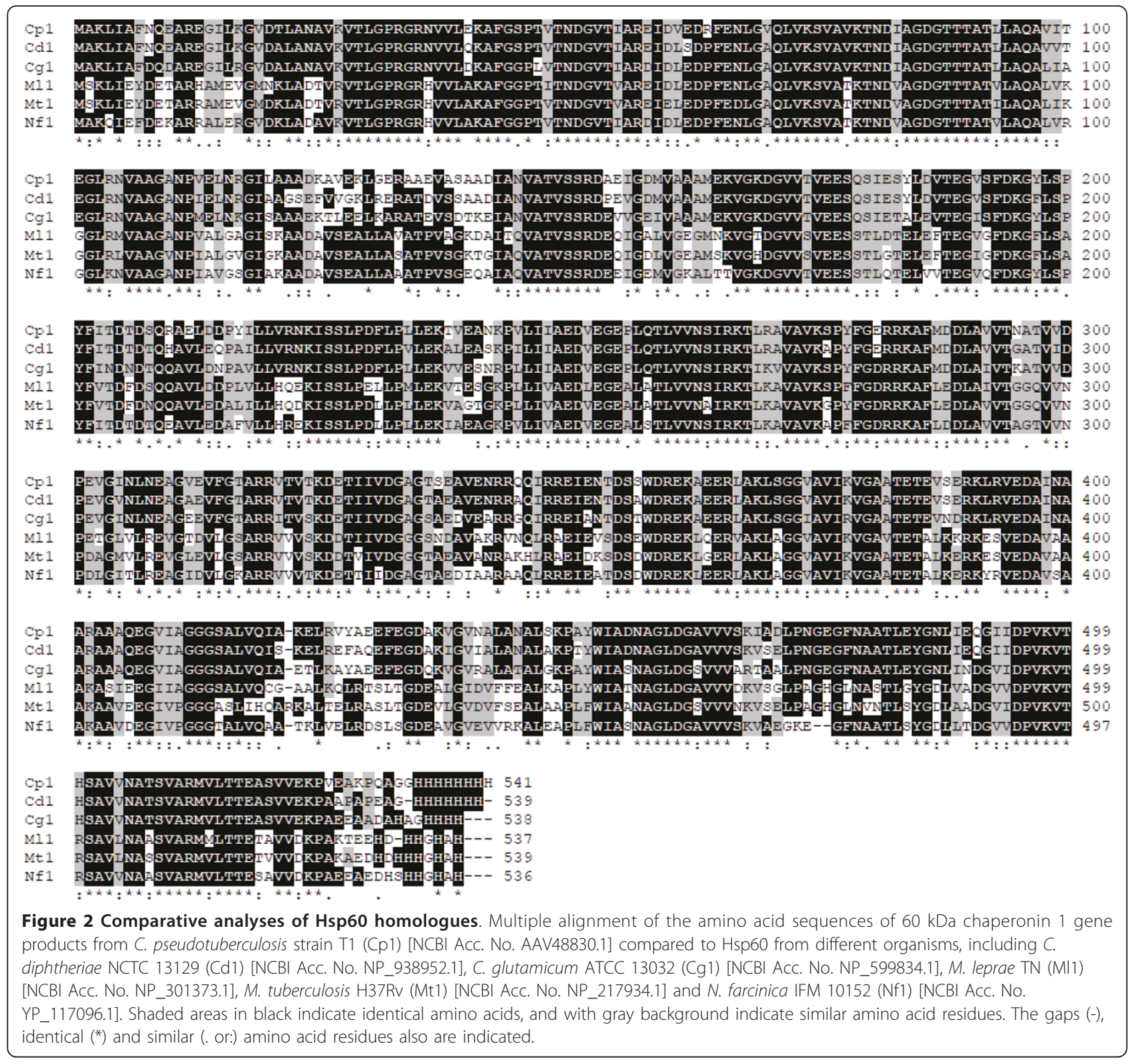

showed cachexia, piloerection, cyanosis, hypothermia and ascitis, all characteristic signs and symptoms of a $C$. pseudotuberculosis infection.

\section{Discussion}

This study was the first to characterize the immunogenic potential of the $h s p 60$ DNA vaccine for protection against the veterinary pathogen C. pseudotuberculosis. The $h s p 60$ DNA vaccine induced a cellular immune response but failed to confer protective immunity to the host, which corroborates a previous study that found that an Hsp60 protein subunit vaccine also did not confer protection [13].
Characterization of the hsp60-hsp10 bicistronic operon

We found that in C. pseudotuberculosis these genes are arranged in a bicistronic hsp60-hsp10 operon, separated by a small sequence of $11 \mathrm{bp}$. The size and organization of the hsp60 gene in C. pseudotuberculosis (1,626 bp) was similar to those described for other bacterial species, such as C. glutamicum (1,617 bp) [23] and R. equi (1,623 bp) [24]. The hsp10 gene (297 bp) has a start codon (GTG), and the predicted molecular weight is $10.6 \mathrm{kDa}$. These characteristics are conserved in the $h s p 10$ genes of other species [25]. Comparative DNA sequence analysis of the $h s p 10$ and $h s p 60$ genes showed significant similarity with genes of microorganisms with 

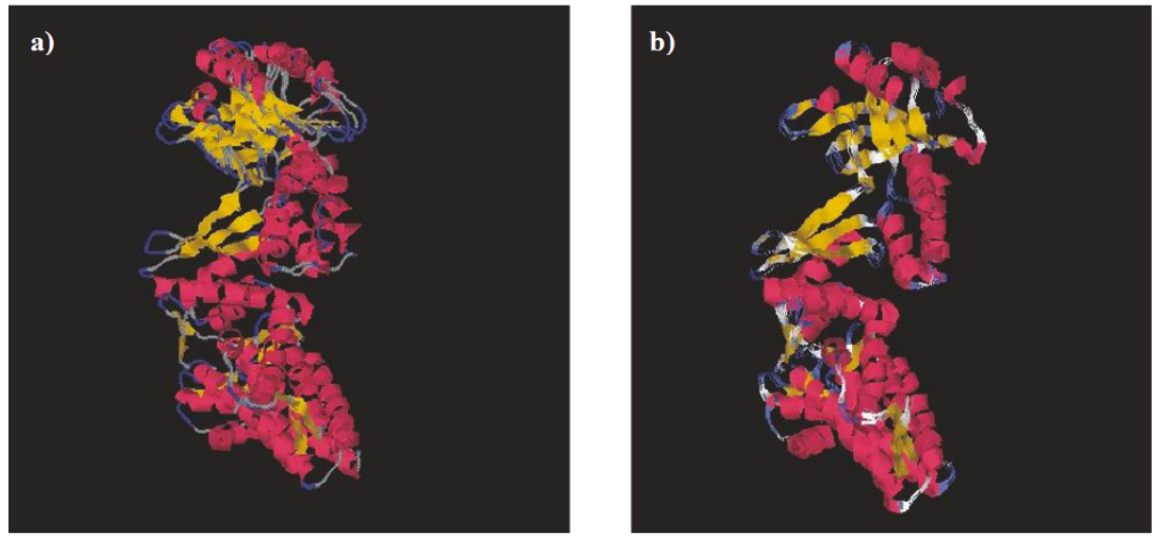

Figure 3 Predictive 3D models of Hsp60. Hsp60 from C. pseudotuberculosis (60 kDa chaperonin 1 gene, AAV48830.1); b) Hsp60 from E. coli, created with MODELLER, based on PDB related structures (1GR5, 1IOK, 1KP8, 1PCQ, 1SJP and 1WE3), as well as on combinatorial modeling. 3D structures are displayed in colored cartoon representations visualized with CHIME http://www.mdl.com. The $\alpha$-helix and $\beta$-pin (loop) repeats of both structures are marked with the same colors.

phylogenetic proximity, especially between two $h s p 60$ paralogs (groEL1 and groEL2) within the Corynebacterium genus [26]. Alignment of amino acid sequences coded by $h s p 60$ revealed a higher identity at the $\mathrm{N}$ - and C- terminal regions. According to Barreiro et al [26] some microorganisms have different functional motifs at the $\mathrm{C}$-terminal ends of the proteins coded by $h s p 60$; there is a string of histidines in groEL1, while groEL2 has a glycine-glycine-methionine (GGM) motif. This putative protein showed a motif containing eight

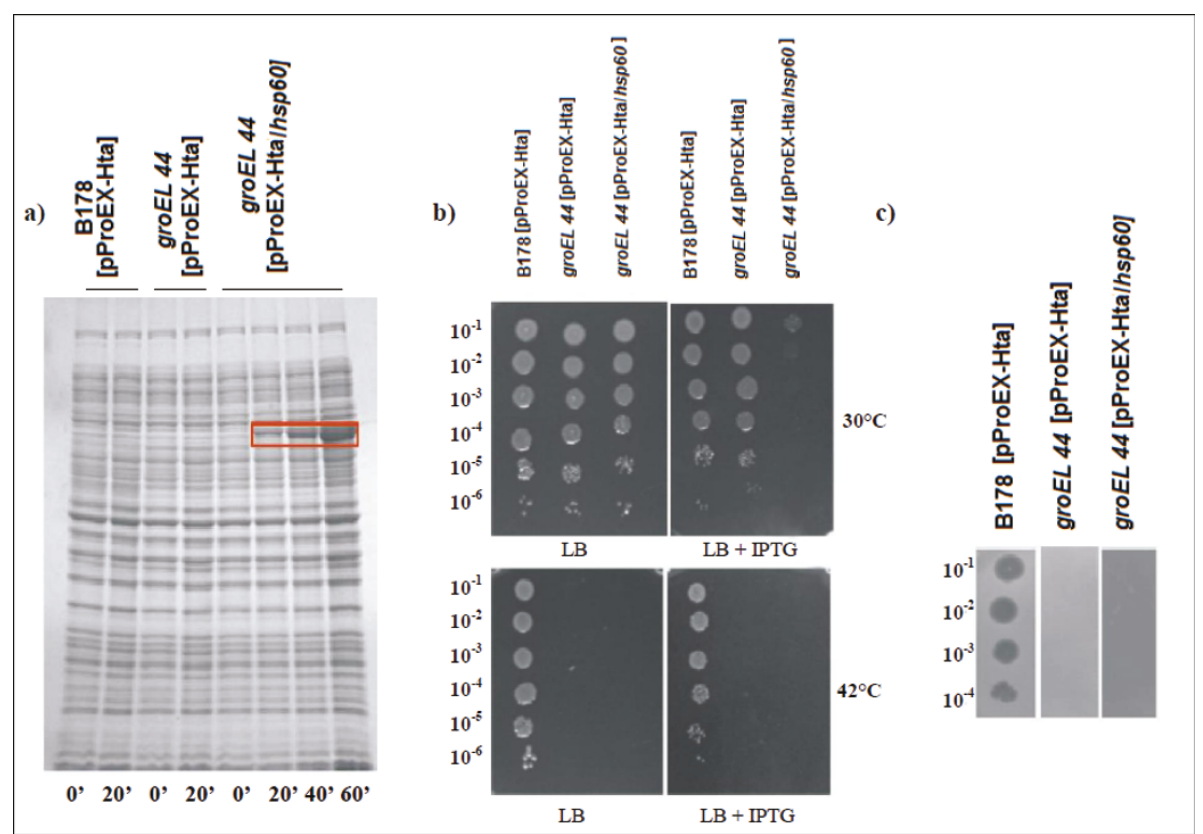

Figure 4 Expression of $C$. pseudotuberculosis Hsp60 protein and complementation assays. a) Expression of C. pseudotuberculosis Hsp60 protein in E. coli groEL44 mutant transformed with the recombinant vector pProEx-Hta:hsp60 (groEL44[pProEx-Hta/hsp60]); E. coli wild-type and mutant transformed with the empty vector (B178[pProEX-Hta] and groEL44[pProEX-Hta], respectively) were used as negative controls. Expression of recombinant protein was analyzed at 0, 20, 40 and 60 min after induction with IPTG. The rectangle indicates the protein expressed; b) Complementation assay after thermal stress. The growth of E. coli wild-type (B178[pProEX-Hta]), groEL44 mutant (groEL44[pProEX-Hta] and groEL44[pProEx-Hta/hsp60]) were evaluated. Cultures were serially diluted $\left(10^{-1}\right.$ to $\left.10^{-6}\right)$, spotted onto the surface of LB agar plates (with and

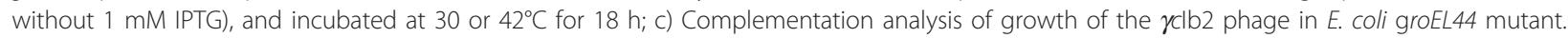
The growth of the phage was evaluated in E. coli wild-type (B178[pProEX-Hta]) and groEL44 mutant (groEL44[pProEX-Hta] and groEL44[pProEX$\mathrm{Hta} / \mathrm{hsp60])}$. The cultures induced with IPTG, plated at the dilutions from $10^{-1}$ to $10^{-4}$, were incubated at $30^{\circ} \mathrm{C}$ for $18 \mathrm{~h}$. 
a)

$\lg \mathbf{G}$
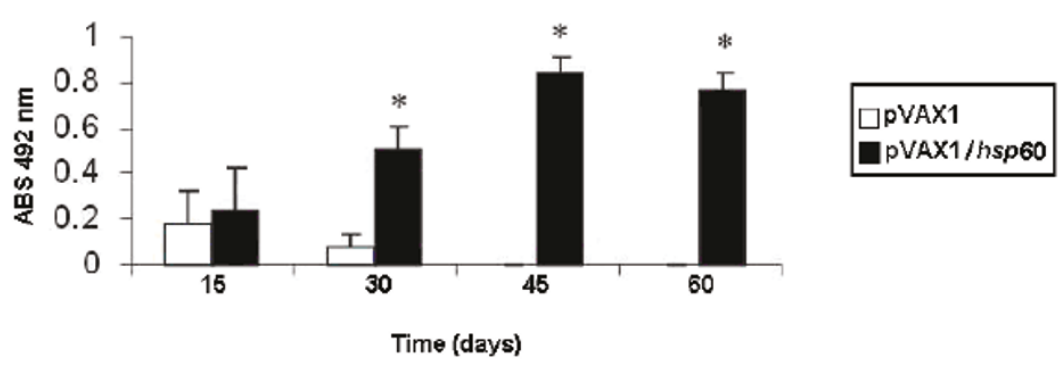

b)
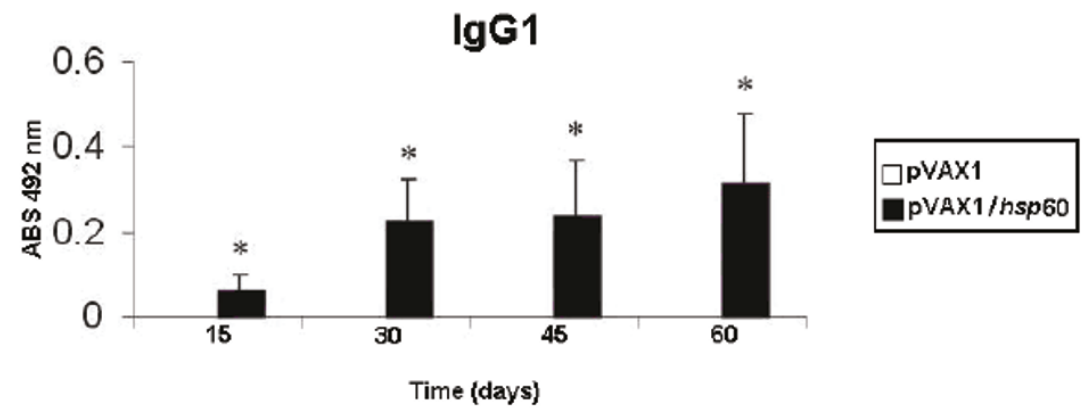

c)

$\lg \mathbf{g} 2 \mathbf{a}$

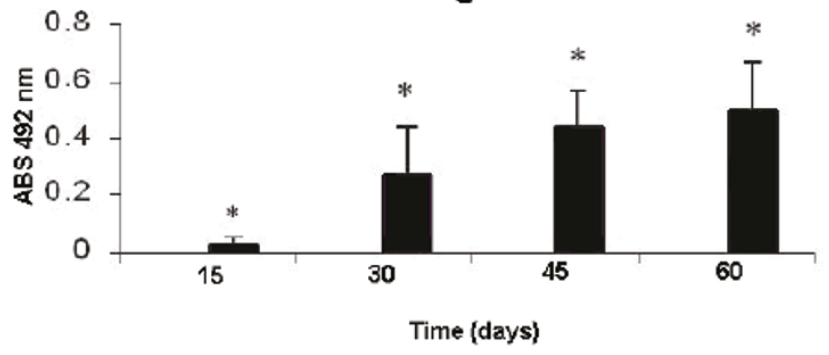

Figure 5 The profile of total anti-Hsp60 IgG antibody response after DNA vaccination in mice. a) IgG antibody titer; b) IgG1 isotype titer; c) IgG2a isotype titer. Groups of mice were immunized with the DNA vaccine as follows: intramuscular injection of vector pVAX1 and

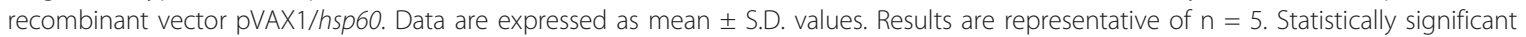
differences between pVAX1/hsp60 and pVAX1 immunized mice are denoted by an asterisk $(p<0.05)$.

histidine residues at the $\mathrm{C}$ terminus, which is characteristic of $h s p 60$ paralog groEL1 protein in actinomycetes [27]. The predicted tertiary structure of the Hsp60 protein showed three functionally distinct domains that are very characteristic of chaperonins: an $\alpha$-helical equatorial, a small intermediate, and a highly flexible apical domain [28].

The high level of similarity between hsp60 of C. pseudotuberculosis and those of other important pathogens, such as M. leprae and M. tuberculosis, is important 
Table 2 IgG1 and IgG2a immune profile induced by vaccination with pVAX1/hsp60 or pVAX1 vectors.

\begin{tabular}{|c|c|c|c|c|c|}
\hline \multirow[t]{3}{*}{ Days $^{a}$} & \multicolumn{5}{|l|}{ Groups } \\
\hline & \multicolumn{2}{|c|}{$\operatorname{lgG1}$} & \multicolumn{2}{|c|}{$\operatorname{lgG} 2 a$} & \multirow[t]{2}{*}{ lgG1/lgG2a ratio } \\
\hline & pVAX1/hsp60 & pVAX1 & pVAX1/hsp60 & pVAX1 & \\
\hline 15 & $0.06 \pm 0.039^{b}$ & $0.002 \pm 0.001$ & $0.03 \pm 0.011^{b}$ & $0.003 \pm 0.002$ & 2.00 \\
\hline 30 & $0.23 \pm 0.094^{b}$ & $0.003 \pm 0.001$ & $0.27 \pm 0.149^{b}$ & $0.002 \pm 0.001$ & 0.85 \\
\hline 45 & $0.24 \pm 0.133^{b}$ & $0.004 \pm 0.002$ & $0.43 \pm 0.114^{b}$ & $0.004 \pm 0.001$ & 0.56 \\
\hline 60 & $0.32 \pm 0.165^{b}$ & $0.003 \pm 0.002$ & $0.49 \pm 0.160^{b}$ & $0.004 \pm 0.003$ & 0.65 \\
\hline
\end{tabular}

${ }^{a}$ Days after the first immunization.

b Significantly different compared to mice immunized with the pVAX1 vector.

because other studies have indicated that mycobacterial Hsp60 is a potential immunodominant target of the humoral and T-cell response in mice and humans [29]. Additionally, high sequence homology of HSPs between different species results in HSPs that have cross-reactive epitopes [30].

Despite high homology between C. pseudotuberculosis hsp 60 and E. coli GroEL, our complementation assay failed to complement the GroEL defect in E. coli. There are several explanations for these results. First, the hsp60 expressed in E. coli may have improperly folded and thus lacked activity to complement GroEL. Second, since HSPs have been reported to adversely affect protein homeostasis and vital intracellular functions [11], overexpression of $h s p 60$ may have reduced cell viability at all concentrations except at the $10^{-1}$ dilution at $30^{\circ} \mathrm{C}$. Third, protein-protein interaction between E. coli GroEL and GroES (the corresponding $h s p 60$ and hsp10 paralogs) is also necessary for cell viability [31]. The GroEL mutant $E$. coli complemented with the C. pseudotuberculosis hsp60 gene did not grow, indicating that there may be little protein-protein interaction between the Hsp60 and E. coli groES proteins. Finally, lack of growth may indicate that the Hsp60 protein cannot function inside E. coli despite protein homology because speciesspecificity of chaperone proteins is complex and is not explained simply by protein homology [32], because the regulatory mechanism of the heat shock response differs among species [33].

E. coli GroEL is also required for the proper growth of bacteriophages, including capsid formation $[27,34]$. The inability of the C. pseudotuberculosis hsp60 gene to support the growth of $\gamma$ phage in the E. coli GroEL mutant suggests that the Hsp60 protein does not perform the specific function of capsid formation inside $E$. coli, again possibly due to incorrect folding.

\section{Immune response to hsp60 DNA vaccine in mice}

Due to the success of DNA-based vaccines using genes encoding HSPs to induce immunity against a variety of pathogens [24], we chose the C. pseudotuberculosis hsp60 gene for the development of a DNA vaccine. Vaccination with the recombinant C. pseudotuberculosis hsp60 antigen induced significant production of specific anti-Hsp60 antibodies. These data indicate that the DNA vaccine (pVAX1/hsp60) generated both IgG1 and IgG2a responses, when administered to BALB/c mice, however, with a tendency towards a Th1-type immune response after 30 days of the first immunization based on reduced IgG1/IgG2a ratio. Nevertheless, DNA immunization with pVAX1/hsp60 conferred no protection against challenge with the pathogen; it did not prevent infection.

The protective efficacy of DNA vaccines has been studied extensively for Mycobacterium tuberculosis. For example, a DNA vaccine encoding the $M$. leprae $h s p 65$ induced protective immunity against tuberculosis challenge in a mouse model [35], and a DNA vaccine with the M. avium hsp65 plasmid elicited a strong protective immune response in lambs and protected against $M$. avium subspecies paratuberculosis infection [36]. However, other studies have shown that a high antibody response induced by DNA vaccines does not always result in protective immunity [24], as we also observed in our study.

In summary, intramuscular administration of $h s p 60$ DNA vaccine in mice induced an immune response but failed to confer protection against infection with $C$. pseudotuberculosis.

\section{Acknowledgements}

This work was supported by FAPEMIG (Fundação de Amparo à Pesquisa do Estado de Minas Gerais, Brasil), CNPq (Conselho Nacional de Desenvolvimento Científico e Tecnológico, Brasil) and FUNCAP (Fundação Cearense de Apoio ao Desenvolvimento Científico e Tecnológico, Brasil).

\section{Author details}

'Departamento de Biologia Geral. Instituto de Ciências Biológicas. Universidade Federal de Minas Gerais. Av. Antonio Carlos, 6627 - Pampulha, CP 486, CEP 31.270-901. Belo Horizonte- MG, Brazil. 'Faculdade de Medicina Veterinária, Núcleo de Genômica e Bioinformática. Universidade Estadual do Ceará. Av. Paranjana, 1700 - Itaperi, CEP 60.740-000. Fortaleza-CE, Brazil. ${ }^{3}$ Departamento de Genética. Instituto de Ciências Biológicas. Universidade Federal do Pará, R. Augusto Corrêa, 01 - Guamá, CP 8607, CEP 66.075-900. Belém-PA, Brazil. ${ }^{4}$ Fundação Oswaldo Cruz. Centro de Pesquisa René Rachou, Av. Augusto Lima, 1715 - Barro Preto, CEP 30.190-002. Belo Horizonte-MG, Brazil. ${ }^{5}$ Department of Biochemistry. University of Gdansk, ul. Bażyńskiego 1a, Postal Code 80-952. Gdańsk, Poland. ${ }^{6}$ Departamento de Ciências da Biointeração. Instituto de Ciências da Saúde. Universidade Federal da Bahia, Av. Reitor Miguel Calmon, s/n - Vale do Canela, CEP 40110100 . Salvador-BA, Brazil. 


\section{Authors' contributions}

$M P C, F A D, S A$, JAM contributed to the design of the study and the data analysis, and wrote the manuscript. FAD and CTF performed the majority of experiments. EW and BL performed the functional characterization assay. DMO, MTST, RM, RWP, SCO, AM and VA were involved in the study design, management and coordination, and the drafting of the manuscript. The authors have read and approved the final draft of the manuscript.

\section{Competing interests}

The authors declare that they have no competing interests.

Received: 27 January 2011 Accepted: 20 July 2011

Published: 20 July 2011

\section{References}

1. Dorella FA, Pacheco LGC, Oliveira SC, Miyoshi A, Azevedo V: Corynebacterium pseudotuberculosis: microbiology, biochemical properties, pathogenesis and molecular studies of virulence. Vet Rev 2006, 37:1-18.

2. Baird GJ, Fontaine MC: Corynebacterium pseudotuberculosis and its role in ovine caseous lymphadenitis. J Comp Path 2007, 137:179-210.

3. Moura-Costa LD, Bahia RC, Carminati R, Vale VLC, Paule BJA, Portela RW, Freire S M, Nascimento I, Schaer R, Barreto LMS, Meyer R: Evaluation of the humoral and cellular immune response to different antigens of Corynebacterium pseudotuberculosis in Canindé goats and their potential protection against caseous lymphadenitis. Vet immunol immunopathol 2008, 126:131-141.

4. Eggleton DG, Middleton HD, Doidge CV: Immunization against ovine caseous lymphadenitis: comparison of Corynebacterium pseudotuberculosis vaccines with and without bacterial cells. Aust Vet $J$ 1991, 68:317-319.

5. Ellis JA, Hawk DA, Mills KW: Antigen specificity and activity of ovine antibodies induced by immunization with Corynebacterium pseudotuberculosis culture filtrate. Vet Immunol Immunopathol 1991, 28:303-316.

6. Chaplin PJ, De Rose R, Boyle JS, McWaters P, Kelly J, Tennent JM, Lew AM, Scheerlinck JPY: Targeting improves the efficacy of a DNA vaccine against Corynebacterium pseudotuberculosis in sheep. Infect Immun 1999, 67:6434-6438.

7. Williamson LH: Caseous lymphadenitis in small ruminants. Vet Clin North Am Food Anim Pract 2001, 17:359-371.

8. Hauet-Broere F, Wieten L, Guichelaar T, Berlo S, van der Zee R, van Eden W: Heat shock proteins induce $T$ cell regulation of chronic inflammation. Ann Rheum Dis 2006, 65:iii65-iii68.

9. Prohászka Z, Füst G: Immunological aspects of heat-shock proteins-the optimum stress of life. Mol Immunol 2004, 41:29-44.

10. Udvarnoki K, Cervenak L, Uray K, Hudecz F, Kacskovics I, Spallek R, Singh M, Füst $\mathrm{G}$, Prohászka Z: Antibodies against $\mathrm{C}$-reactive protein cross-react with 60-kilodalton heat shock proteins. Clin Vacc Immunol 2007, 14:335-341.

11. Pockley AG: Heat shock proteins in health and disease: therapeutic targets or therapeutic agents? Exp Rev Mol Med 2001, 3:1-21.

12. Segal BH, Wang XY, Dennis CG, Youn R, Repasky EA, Manjili MH, Subjeck JR: Heat shock proteins as vaccine adjuvants in infections and cancer. Drug Discovery Today 2006, 11:534-530.

13. Pinho JMR, Dorella FA, Coelho KS, Fonseca CT, Cardoso FC, Meyer R, Portela RWD, Oliveira SC, Miyoshi A, Azevedo V: Immunization with recombinant Corynebacterium pseudotuberculosis heat- shock protein (Hsp)-60 is able to induce an immune response in mice, but fails to confer protection against infection. Open Vet Sci J 2009, 3:22-27.

14. Pacheco LGC, Pena RR, Castro TLP, Dorella FA, Bahia RC, Carminati R, Frota MNL, Oliveira SC, Meyer R, Alves FSF, Miyoshi A, Azevedo V: Multiplex PCR assay for identification of Corynebacterium pseudotuberculosis from pure cultures and for rapid detection of this pathogen in clinical samples. J Med Microbiol 2007, 56:480-486.

15. Sambrook J, Russell DW: In Molecular Cloning: a Laboratory Manual.. 2 edition. Edited by: Cold Spring Harbor. New York: Cold Spring Harbor Laboratory; 2001:

16. Altschul SF, Madden TL, Schäffer AA, Zhang J, Zhang Z, Miller W, Lipman DJ: Gapped BLAST and PSI-BLAST: a new generation of protein database search programs. Nucleic Acids Res 1997, 25:3389-3402.
17. Marti-Renom MA, Stuart A, Fiser A, Sánchez R, Melo F, Sali A: Comparative protein structure modeling of genes and genomes. Annu Rev Biophys Biomol Struct 2000, 29:291-325.

18. Gasteiger E, Hoogland C, Gattiker A, Duvaud S, Wilkins MR, Appel RD, Bairoch A: Protein identification and analysis tools on the ExPASy Server. In The Proteomics Protocols Handbook.. 2 edition. Edited by: John M Walker. NJ: Humana Press; 2005:571-601.

19. Zeilstra-Ryalls J, Fayet O, Baird L, Georgopoulos C: Sequence analysis and phenotypic characterization of groEL mutations that block I and T4 bacteriophage growth. J Bacteriol 1993, 175:1134-1143.

20. Kumar CMS, Khare G, Srikanth CV, Tyagi AK, Sardesai AA, Mande SC: Facilitated oligomerization of mycobacterial GroEL: evidence for phosphorylation-mediated oligomerization. J Bacteriol 2009, 121:6525-6538

21. Sambroock J, Fritsch EF, Maniats T: In Molecular Cloning: a Laboratory Manual.. 2 edition. Edited by: Cold Spring Harbor. New York: Cold Spring Harbor Laboratory; 1989:.

22. Héchard C, Grépinet $\mathrm{O}$, Rodolakis A: Molecular cloning of the Chamydophila abortus groEL gene and avaluation of its protective efficacy in a murine model by genetic vaccination. J Med Microbiol 2004, 53:861-868,

23. Barreiro C, González-Lavado E, Pátek M, Martín JF: Transcriptional analysis of the groES-groEL1, groEL2 and dnaK genes in Corynebacterium glutamicum: characterization of heat shock-induced promoters. $J$ Bacteriol 2004, 186:4813-4817.

24. Vanniasinkam T, Barton MD, Heuzenroeder MW: The immunogenicity of Rhodococcus equi GroEL2 based vaccines in a murine model. Vet immunol immunopathol 2004, 98:91-100.

25. Kim SN, Kim SW, Pyo SN, Rhee DK: Molecular cloning and characterization of groESL operon in Streptococcus pneumoniae. Mol Cells 2001, 11:360-368.

26. Barreiro C, González-Lavado E, Brand S, Tauch A, Martín JM: Heat shock proteome analysis of wild-type Corynebacterium glutamicum ATCC 13032 and a spontaneous mutant lacking GROEL1, a dispensable chaperone. J Bacteriol 2005, 187:884-889.

27. Ojha A, Anand M, Bhatt L, Jacobs WR, Hatfull G: GroEL1: a dedicated chaperone involved in mycolic acid biosynthesis during biofilm formation in Mycobacteria. Cell 2005, 123:861-873.

28. Braig K: Chaperonins. Curr Opin Struct Biol 1998, 8:159-165.

29. Young RA: Stress proteins and immunobiology. Annu Rev Immunol 1990, 8:401-20.

30. Qamra R, Shekhar C, Mande SC, Coates ARM, Henderson B: The unusual chaperonins of Mycobacterium tuberculosis. Tuberculosis 2005, 85:385-394.

31. Radulovic S, Rahman MR, Beier MS, Azad AF: Molecular and functional analysis of the Rickettsia typhi groESL operon. Gene 2002, 298:41-48.

32. Kuchanny- Ardigo D, Lipin'ska B: Cloning and characterization of the groE heat-shock operon of the marine bacterium Vibrio harveyi. Microbiology 2003, 149:1483-1492

33. Eom CY, Kim E, Ro YT, Kim SW, Kim YM: Cloning and molecular characterization of groESL heat-shock operon in Methylotrophic bacterium Methylovorus sp. Strains SS1 DSM 11726. J Biochem Mol Biol 2005, 38:695-702.

34. Lee WT, Terlesky KC, Tabita FR: Cloning and characterization of two groESL operons of Rhodobacter sphaeroides: transcriptional regulation of the heat-induced groESL operon. Amer Soc Microb 1997, 179:487-495.

35. Silva CL, Bonato VL, Coelho-Castelo AA, Souza AO, Santos SA, Lima KM, Faccioli LH, Rodrigues JM: Immunotherapy with plasmid DNA encoding mycobacterial Hsp65 in association with chemotherapy is a more rapid and efficient form of treatment for tuberculosis in mice. Gene Ther 2005, 12:281-287.

36. Sechi LA, Mara L, Cappai P, Frothingam R, Ortu S, Leoni A, Ahmed N, Zanetti S: Immunization with DNA vaccines encoding different mycobacterial antigens elicits a Th1 type immune response in lambs and protects against Mycobacterium avium subspecies paratuberculosis infection. Vaccine 2006, 24:229-235.

doi:10.1186/1756-0500-4-243

Cite this article as: Costa et al:: Molecular characterization of the Corynebacterium pseudotuberculosis hsp60-hsp10 operon, and evaluation of the immune response and protective efficacy induced by $h s p 60$ DNA vaccination in mice. BMC Research Notes 2011 4:243. 